\title{
EL “ESTADO DE ARAUCO” FRENTE A LA CONQUISTA ESPAÑOLA: ESTRUCTURACIÓN SOCIOPOLÍTICA Y RITUAL DE LOS ARAUCANO-MAPUCHES EN LOS VALLES NAHUELBUTANOS DURANTE LOS SIGLOS XVI Y XVII
}

\author{
THE “ARAUCO STATE” AGAINST THE SPANISH CONQUEST: RITUAL AND \\ SOCIO-POLITICAL STRUCTURE OF THE ARAUCANO-MAPUCHES IN THE \\ NAHUELBUTA VALLEYS DURING THE 16TH AND 17TH CENTURIES
}

\author{
José Manuel Zavala Cepeda y Tom D. Dillehay ${ }^{2,3}$
}

\begin{abstract}
Este artículo presenta evidencias arqueológicas y etnohistóricas que muestran la complejidad de la organización sociopolítica de las poblaciones que habitaban los valles que entrecruzan y circundan la cordillera de Nahuelbuta durante el siglo XVI y principios del siglo XVII, particularmente en el valle de Purén-Lumaco. La hipótesis que se sostiene es que la estructura sociopolítica, la densidad demográfica y las características económicas y culturales de las poblaciones de dicha área presentan una mayor complejidad y dimensiones superiores a lo que comúnmente se admite en la literatura arqueológica, histórica y antropológica. Las formas de organización sociopolíticas y los modos de asentamiento de las poblaciones araucano-mapuches de los siglos XVI y principios del siglo XVII tenderían a aproximarse, desde esta perspectiva, a modelos complejos característicos del mundo andino.

Palabras claves: Estado de Arauco, araucanos siglos XVI y XVII, mapuches siglos XVI y XVII, etnohistoria cordillera de Nahuelbuta.
\end{abstract}

This article discusses the archaeological and ethnohistorical evidence for the socio-political organization of the indigenous populations of the interconnected valleys of the Nahuelbuta mountain range in south-central Chile. The argument is that the sociopolitical structure, the demographic density, and the cultural and economic characteristics of these populations were much more advanced and complex than previously discussed in the archaeological, historical, and anthropological literature. The form of the socio-political organization and the settlement pattern of the Araucanian-Mapuche populations in the study area from the 16th to 17th centuries are hypothesized in terms of complex models of the Andean world.

Key words: State of Arauco, Araucanian 16th and 17th centuries, Mapuche 16th and 17th centuries, ethnohistory of the Cordillera de Nahuelbuta.

La realidad sociocultural de la región situada entre los ríos Bío-Bío y Toltén a mediados del siglo XVI constituye aún una incógnita en muchos aspectos, a pesar de la existencia de tempranos registros hispanos ${ }^{1} \mathrm{y}$ de una abundante bibliografía ${ }^{2}$. Con mucha frecuencia se han realizado generalizaciones y simplificaciones con respecto a los comportamientos culturales de sus habitantes y a las características sociopolíticas de los diversos grupos que ha sido posible identificar. Particularmente problemáticas han sido las inexactitudes y divergencias espaciotemporales que desde el texto fundador de Alonso de Ercilla y Zúñiga, La Araucana (1845 [1569]), han acompañado las descripciones de los araucanos o mapuches ${ }^{3}$ y de Arauco.
Un elemento de confusión suplementario ha sido la utilización, por autores y fuentes hispanas del siglo XVI, del término "estado" para referirse a parte de esta región, lo que ha generado diversas interpretaciones con respecto a esta particularidad denominativa utilizada tanto en singular, "el estado", como en plural, "los estados".

El problema de saber a qué y por qué se denominó "el Estado de Arauco" o "los estados de Arauco" ha sido abordado ya por Alberto Medina (1974) y, recientemente, por Goicovich (2002). Volvemos sobre esta cuestión al inicio de este artículo para despejar el camino hacia una mejor comprensión del paisaje sociocultural de esta área en el siglo XVI; luego se releen los materiales históricos desde una

\footnotetext{
Universidad Católica de Temuco, Escuela de Antropología, Casilla 15-D, Temuco-Chile.jmzavala@uct.cl

Department of Anthropology, Vanderbilt University, Nashville, EEUU. tom.d.dillehay@ vanderbilt.edu

Instituto de Ciencias Sociales, Universidad Austral de Chile, Valdivia.
} 
perspectiva antropológica para posteriormente contrastarlos con la evidencia arqueológica relativa al valle de Purén-Lumaco.

\section{El Estado de Arauco en el Siglo XVI}

La lectura de diversos documentos hispanos del siglo XVI -particularmente de dos textos clásicos sobre los araucano-mapuches: La Araucana (Ercilla y Zúñiga 1845 [1569]) y el informe de Miguel de Olaverría (1852 [1594] $)^{4}$ - nos permite afirmar que el llamado "Estado de Arauco" correspondía a una gran unidad sociopolítica que articulaba un conjunto de valles que atraviesan y circundan la cordillera de Nahuelbuta, cubriendo una amplia área geográfica situada entre el río Bío-Bío por el norte, el río Imperial por el sur, el océano Pacífico por el oeste y el llano central por el este ${ }^{5}$. En este sistema, la cordillera de Nahuelbuta no constituía un espacio marginal o periférico, sino más bien un eje central a partir del cual se articulaban y conectaban los valles.

El análisis de los datos documentales del siglo XVI nos lleva a refutar la aparente localización del llamado "estado de Arauco" exclusivamente en el valle de Arauco, pues entendemos que los acontecimientos y dinámicas descritos en las crónicas y testimonios hispanos de la época se desarrollaron en un área mucho más extensa, que corresponde en términos generales al conjunto de valles y montañas que conforman la cordillera de Nahuelbuta o se desprenden de ella. En este sentido, la llamada "provincia de Arauco" sólo constituía una parte del sistema al que hacían referencia los hispanos con el calificativo de Estado (o los estados) de Arauco. $\mathrm{Al}$ respecto, coincidimos con el planteamiento de Francis Goicovich (2002), quien en un bien documentado y pormenorizado trabajo analiza el origen del denominado estado "indómito" a partir de una lectura crítica de la obra de Ercilla 6 .

Cabe precisar que el término "Estado" era utilizado con cierta liberalidad semántica en los documentos coloniales, lo que sin duda contribuye a generar confusión a la hora de determinar las dimensiones geográficas del estado (o los estados) de Arauco. Así, por ejemplo, en La Araucana de Ercilla (1845 [1569]) se aprecia una nítida contradicción entre lo que el autor denomina el "Estado de Arauco" y el área cubierta por los acontecimientos que describe. En efecto, al final del tomo primero de su obra, Ercilla entrega una muy circunscrita definición del Estado de Arauco; dice:
El estado de Arauco es una provincia pequeña de veinte legua de largo y siete de ancho poco mas ó menos que produce la gente mas belicosa que ha habido en las Indias y por eso es llamado el estado indómito: llamándose los Indios dél Araucanos tomando el nombre de la provincia (Ercilla 1845;I:322).

Sin embargo, gran parte de los acontecimientos que relata el poeta conquistador ocurrieron en otros valles o provincias de la macroárea de Nahuelbuta y hacen referencia a jerarquías políticas y poblaciones asentadas en territorios que se situaban fuera de lo que él denomina explícitamente el estado o provincia de Arauco ${ }^{7}$.

Esta flexibilidad terminológica se trasluce particularmente en el uso variable de la pluralización del término estado asociado al nombre de Arauco; de esta manera, a veces se dice "el estado" y otras "los estados" de Arauco.

Hace ya algunos años, Alberto Medina (1974-75) abordó esta dificultad de saber a qué correspondía exactamente el estado de Arauco. El problema comprende dos aspectos: en primer lugar, conocer qué entendían específicamente los españoles del siglo XVI por estado y, en segundo lugar, determinar qué territorios lo comprendían.

Respecto del primer punto, Medina (197475:144) señala que el concepto de estado de finales de la Edad Media era diferente del clásico y del moderno, pues en esa época cuando se concedía a una persona el derecho de uso de un territorio se le delegaba al mismo tiempo la autoridad sobre su gente. En este sentido, la utilización del concepto de estado podría hacer referencia a la existencia de un sistema político de tipo señorial, en el cual un Señor ejerce el dominio y autoridad sobre un territorio y su gente; en este caso particular, el conquistador Pedro de Valdivia.

La argumentación de Medina tiende a ratificar la interpretación de sus predecesores, en el sentido de que el uso reservado del término estado para Arauco se debería exclusivamente al hecho de haber sido este territorio una especie de feudo privativo de Valdivia y por lo tanto esta denominación expresaría una situación creada por la presencia hispana.

Sin embargo, no podemos descartar - sin necesariamente contradecir la interpretación anterior- que los españoles designaran de un modo tan peculiar este territorio porque encontraron allí 
ciertas particularidades sociopolíticas preexistentes que sobresalían en comparación con otras áreas de poblamiento indígena y que fueran justamente dichas particularidades las que alentaron a Valdivia a tratar de reservarse para sí este espacio geográfico.

En su Tesoro de la lengua castellana publicado en 1611, Cobarruvias señala que estado, entre otras acepciones, "se toma por el gobierno de la persona real, y de su reyno, para su conservación, y aumento" (Cobarruvias 1994 [1611]:382). Es verdad que no aparece explícitamente en Cobarruvias la equivalencia entre estado y otras formas de gobierno fuera del monárquico, aunque un autor de la talla de Sánchez Agesta (1959) considera el concepto de estado como sinónimo de república en su estudio sobre dicho concepto en el pensamiento español del siglo XVI. De existir equivalencia entre los conceptos de república y Estado en el vocabulario hispano del siglo XVI, podría afirmarse sin dificultad que es muy probable que los españoles hayan usado explícitamente el término estado porque percibieron en esta área un sistema político indígena particularmente organizado que podían describir como una especie de república ${ }^{8}$; concepto que la tradición escolástica hispana había bien integrado de los autores griegos y que expresaba diversas formas de gobierno, no sólo la monárquica, tal como lo señala Vitoria (1934 [1539]) y lo especificará posteriormente el diccionario de autoridades de 1732 al definir el concepto de Estado: "se toma también por el país y dominio de un Rey, República o Señor de vasallos" (RAE 1979:II). Es decir, el concepto de Estado entendido como república no está reservado exclusivamente a una forma de dominio de tipo feudal, como lo piensa Medina, sino también a las de tipo monárquico y republicano (democrático) ${ }^{9}$. En consecuencia, no existe motivo de peso para pensar que la acepción de Estado -que incluye al dominio real y al republicanohaya sido desconocida durante el siglo XVI y, por lo tanto, dicho término pudo haber servido desde los inicios de la conquista hispana para designar un territorio con una forma de gobierno indígena no personalizado en la figura de un Monarca o Señor, pero lo suficientemente organizado como para que los españoles lo asociaran a la idea de república y lo calificaran entonces como un Estado.

Respecto del segundo punto, es decir, saber qué territorios comprendía el denominado estado de Arauco, Alberto Medina plantea que el problema consiste en determinar hasta dónde se extendía el señorío de Pedro de Valdivia, compartiendo de esta manera la idea, expresada por diversos autores antiguos y modernos, de que esta denominación sui generis provendría del hecho de haberse constituido en Chile un gran dominio particular reservado al conquistador Pedro de Valdivia al interior del cual otros encomenderos no podían ejercer derechos ${ }^{10}$.

Desde nuestra perspectiva, las confusiones y diferencias con respecto a delimitaciones geográficas, orígenes de topónimos y construcción de etnocalificativos que se aprecian en las fuentes hispanas se deben, en gran medida, a la superposición de sistemas de estructuración sociopolítica coloniales sobre bases organizativas prehispánicas que los observadores peninsulares no querían o no podían reconocer con exactitud. Por otra parte, no olvidemos que se trata de territorios que estaban siendo desarticulados y rearticulados por la conquista española y por la resistencia indígena, por tanto sus límites geográficos eran necesariamente móviles y variaban en función de los avances, retrocesos y redefiniciones de los sistemas de alianzas de unidades políticamente autónomas.

Más allá del problema terminológico, los diversos testimonios del siglo XVI permiten afirmar que una de las principales áreas de enfrentamiento de la llamada guerra de Arauco abarcaba la serie de valles y macizos que conforman y circundan la cordillera de Nahuelbuta. Ahora bien, dichos documentos son explícitos en señalar que algunos territorios de este gran espacio - generalmente descritos como valles y designados como provincias- eran las piezas fundamentales de la resistencia indígena del sur de Chile.

En consecuencia, es posible sostener que la designación "estado de Arauco" da cuenta de la existencia, al menos desde mediados del siglo XVI, de un gran espacio geográfico constituido en torno a la cordillera de Nahuelbuta donde operaba un sistema de alianzas de unidades político-territoriales claramente distinguibles por su capacidad de resistencia y dinamismo; se trataba de una suerte de federación de valles que se interconectaba a través de la cordillera y que, en ciertas ocasiones, actuaba conjuntamente en acciones militares o de negociación con los nuevos invasores.

\section{Las Cuatro Grandes Provincias del Estado}

Al comparar diversas fuentes relativamente tempranas se configura una tendencia que nos permite 
señalar que eran cuatro las provincias principales que lideraban el estado (o los estados) de Arauco. Se trataba fundamentalmente de cuatro grandes cuencas o conjuntos de cuencas que se desprenden de la cordillera de Nahuelbuta: Arauco, Tucapel, Purén-Lumaco y Mareguano-Catiray ${ }^{11}$. En este punto diferimos del planteamiento de Francis Goicovich (2002:83), retomado por Foerster (2004:77) quien, aunque señala acertadamente que el estado de Arauco era una macroalianza de grandes unidades sociopolíticas que iba más allá de la llamada provincia de Arauco, limita su número a tres componentes, a saber, las provincias de Arauco, de Tucapel y de Purén, olvidando un cuarto componente, la provincia de Mareguano.

En efecto, no es posible dejar de señalar que en diversas fuentes del siglo XVI se establece que hay cuatro territorios especialmente importantes en el sistema defensivo indígena del sur del río Bío-Bío: Arauco, Tucapel, Purén y Mareguano. Es verdad que las fuentes no siempre son explícitas e inequívocas al respecto. El propio Luis de Valdivia, quien escribe a principios del siglo XVII, es contradictorio sobre este punto ${ }^{12}$, sin embargo, la tendencia de los testimonios tempranos va en el sentido que señalamos. Así, por ejemplo, Rodrigo de Quiroga señalaba al Rey en 1576:

Mandame Vuestra Magestad Destierre Algunos yndios de los bulliciosos Para las provincias del Perú. En entrando que entre Por los estados de mareguano Purén Arauco y tucapel que son los que hazen la mas guerra En este Reino Procurare aver a las manos assi Por vía de paz como de guerra los mas de los yndios belicossos con El Menor desvío que yo Pudiere de los quales convenía desterrar Alguna buena parte dellos de su naturaleza y trasplantallos en los valles y tierras fértiles anssi desta ciudad de Santiago como de la Serena Lo qual Ponre En Execución y castigo de sus delitos [...]. (Rodrigo de Quiroga al Rey, Santiago, 12 de febrero de 1576 f.[5]. AGI, Ch.18, destacado nuestro).

Hacia la misma época, Juan Ruiz de Gamboa expresaba la necesidad de hacer la guerra a las dichas "provincias" para asegurar la extracción del oro de la Imperial, escribía:
La Imperial es El prinçipio de La guerra prinçipal y haçiendo esto los veçinos haga El governador my señor haçer un fuerte y haçer alto sobre Las minas q En Efecto son muy rricas y En muchas partes y desde allí haçiendo este Efecto salga capitán a haçer La guerra a las provinçias de puren tucapel arauco mareguano [-----] por manera que del trabajo bamos sacando fruto i que a esta riqueza vengan con sus quadrillas a sacar oro de todas las çiudades de arriva demas desto ay otro Efecto bueno En esto que En haçer alto en estas minas haçen espaldas a lo de los indios alterados de las çiudades de arriva. (Juan Ruiz de Gamboa a Vuestra Excelencia [1579], f.[5]. AGI, Ch.31, destacado nuestro).

Trece años más tarde, Alonso de Sotomayor especificaba los cuatro territorios que constituían el "motor" de la guerra; decía:

\section{[...] di vuelta a Purén, Tucapel, Arauco y Mareguano, que son los lebos y llaves mas principales de la guerra desde la Imperial hasta biobio y pasé por todo lo que está de guerra en las costas y en los llanos de estos contornos sin sucederme guarazaba ni rencontrar ninguno por que no se concertaron las juntas que suelen hazer ni les di tiempo para ello (Alonso de Sotomayor, 4 de Enero de 1589. ANCh, AMV, vol. 1, f. 82v., destacado nuestro).}

Hemos establecido la ubicación geográfica aproximada de estas cuatro provincias en el mapa siguiente (Figura 1), el cual es sólo referencial y no exacto. En el diagrama que sigue (Figura 2 ) hemos representado esquemáticamente el posicionamiento geográfico de las cuatro provincias tomando como eje el macizo nahuelbutano. La representación visual de esta alianza de cuatro grandes provincias es bastante sugerente y nos permite plantear como hipótesis al menos dos afirmaciones:

En primer lugar, que la recurrencia observada posteriormente entre los mapuches de sistemas compuestos por cuatro partes, ya sea en el dominio político, como ocurre con los cuatro vutanmapu en los Parlamentos del siglo XVIII (Zavala 1998), ya sea en el dominio simbólico, como es el caso del 


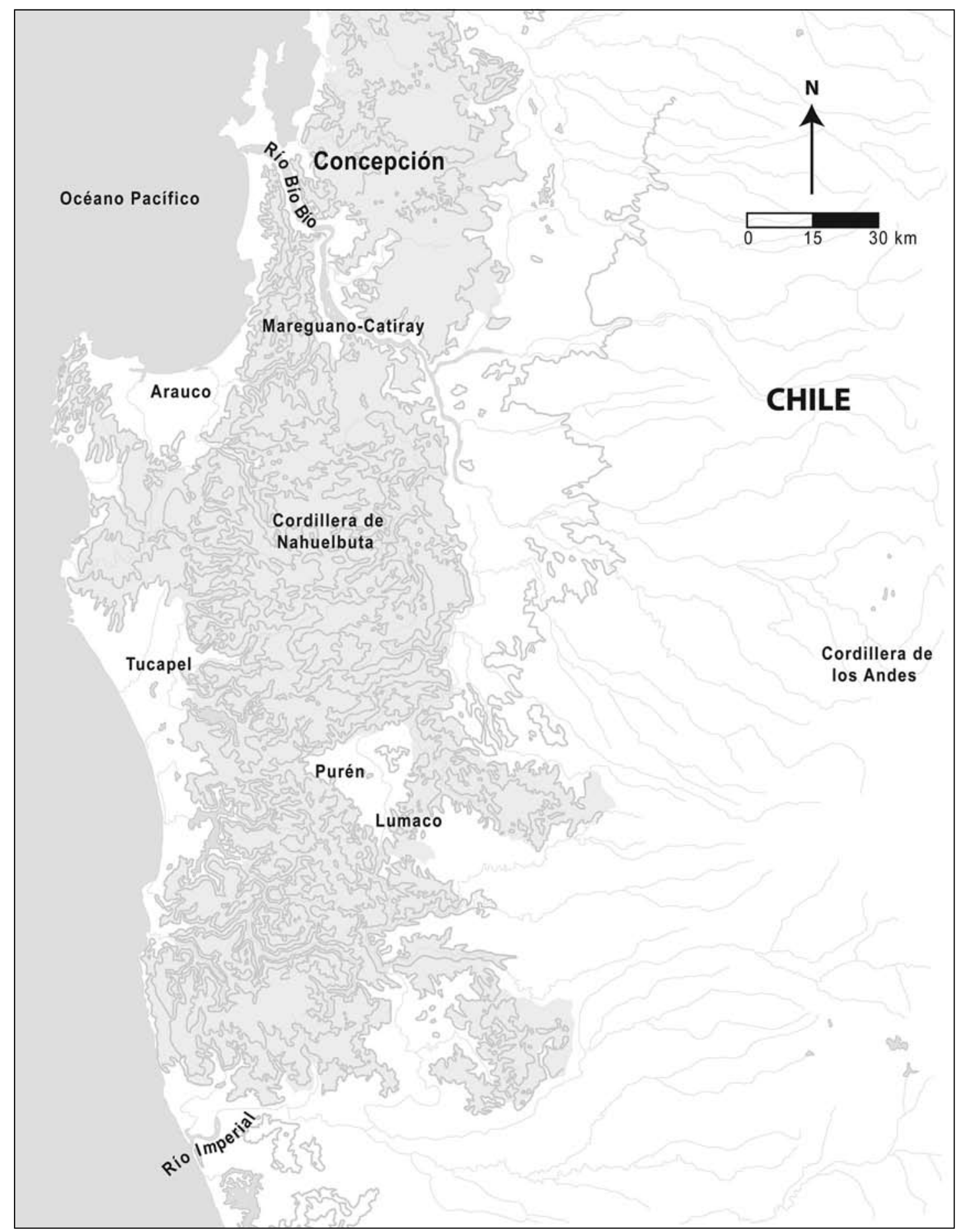

Figura 1. Mapa con la ubicación aproximada de las cuatro provincias del Estado de Arauco. Map showing the approximate location of the four provinces of the Arauco State. 


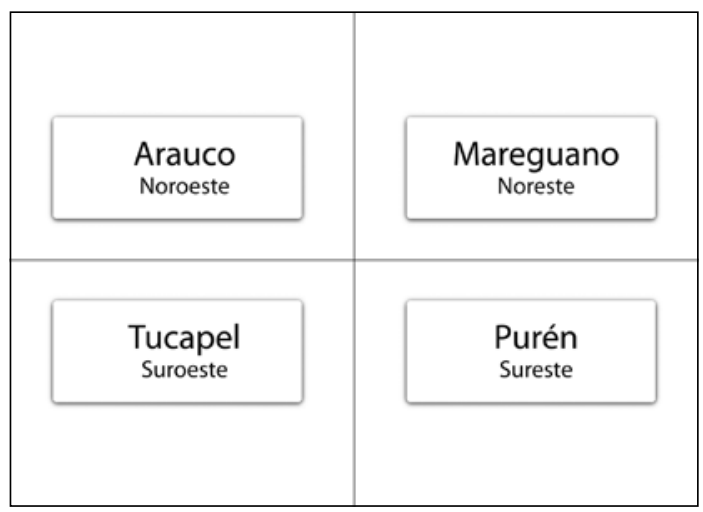

Figura 2. Diagrama del posicionamiento geográfico de las cuatro provincias en relación con la cordillera de Nahuelbuta.

Schematic diagram of the position of the four provinces in relation to the Nahuelbuta cordillera.

kultrun actual (Grebe 1973), tiene antecedentes muy tempranos, con toda probabilidad prehispánicos. En efecto, si la estructuración cuatripartita del territorio fue operativa en la segunda mitad del siglo XVI y se mantuvo a lo largo de los siglos, necesariamente las bases cognitivas, lingüísticas y culturales que la hicieron posible estaban ya arraigadas al momento del primer contacto con los hispanos.

En segundo lugar, que esta representación y división del territorio en cuatro secciones tiene una gran semejanza con los modelos cuatripartitos de estructuración político-territoriales del mundo andino establecidos por Murra (1975), Rostowrowski (1988) y Netherly (1993) y, por lo tanto, puede indicar un contacto cultural directo o indirecto muy temprano entre los habitantes de Nahuelbuta y el mundo andino ${ }^{13}$.

\section{Primera Lectura Hispana de la Realidad Sociopolítica de Nahuelbuta: Las Provincias y sus Levo}

Cada una de las grandes unidades políticoterritoriales designadas a veces como provincias y otras como estados en las fuentes hispanas del siglo XVI se presenta a su vez como un sistema de alianzas de unidades territoriales menores situadas generalmente al interior o próximas al valle principal que da nombre a la provincia o estado. Dichas unidades menores son designadas en los documentos tempranos con el término de levo. Es sobre la base de los levo que los españoles procedieron a repartir la población local y a organizar la dominación sobre ella al sur del río Bío-Bío; así lo señala el propio conquistador Pedro de Valdivia, pues al fundar la ciudad de La Imperial en 1551, dice:

\section{Luego repartí a todos los caciques que hay del río para acá sin dar ninguno de los de la otra parte por sus levos cada uno de su nombre que son como apellido y a donde los yndios rreconocen la subjection a sus superiores (P. Valdivia al Rey, Concepción, 26 Sep. 1551, f. [2]. AGI, Ch.18, destacado nuestro).}

Queda claro en la afirmación de Valdivia que el levo correspondía a una unidad sociopolítica preexistente e identificable por un nombre reconocido por sus habitantes como si fuera un apellido; podemos suponer que dicha apelación hacía referencia a un patrilinaje dominante en torno al cual se aglutinaba el levo y a partir del cual se estructuraba su sistema de autoridad específico, pues en el levo -dice Valdivia- se reconocía la sujeción a los superiores. Para los españoles, sin duda era muy importante contar con un sistema de autoridad local que pudiese ser recuperado y puesto al servicio del régimen de encomiendas.

Al parecer, así ocurrió, por lo menos en los primeros tiempos, pues ya durante el primer decenio de contacto, una buena parte de la población de la macroárea de Nahuelbuta era distribuida entre los conquistadores españoles que comenzaban a asentarse en las ciudades de La Imperial, Angol y Cañete y en las casas fuertes de Arauco y Purén. La temprana organización de encomiendas en la región sólo puede explicarse por la preexistencia de estructuras sociopolíticas capaces de ser rápidamente puestas al servicio de las explotaciones auríferas y de los núcleos de poblamiento hispano que se establecieron en las proximidades de la cordillera de Nahuelbuta ${ }^{14}$. La organización en levo debe de haber sido lo bastante generalizada y sólida en esta región como para permitir una rápida puesta en marcha del modelo hispano de conquista basado en el trabajo indígena.

Respecto de la distribución de la población a través del sistema de levo, tenemos información temprana relativa a la provincia o estado de Tucapel en un informe de Francisco de Ulloa de 1563 (AGI, Ch.30), donde se presenta una lista de repartimientos reasignados. Allí se señalan nueve repartimientos redistribuidos, entre los que figuran 
tres con sus nombres originales: Paicaví, Ongolmo y Licura. Si bien Ulloa no precisa que se trataba de levo, sabemos por lo señalado por Valdivia en la cita anterior que la población era repartida a base de los levo. Además, como veremos en el documento siguiente, Paicaví, Ongolmo y Licura serán designados explícitamente como levo cuatro años más tarde.

En efecto, en un testimonio del escribano del cabildo de la ciudad de Cañete, Juan Muñoz de Ávila, de octubre de 1567 , se entrega la lista de los levo de guerra de Tucapel que daban la paz. En dicho documento, el escribano relata que cuando Martín Ruiz de Gamboa asume como gobernador en septiembre de dicho año, toda la "tierra y costa de Tucapel estaba de guerra desde el levo de Quiapo hasta Tirúa" (AGI, Ch.30, destacado nuestro) y que luego de haber derrotado a los enemigos que se habían fortificado en Lincoya, el nuevo gobernador "trajo toda la tierra de paz sin quedar ningún repartimiento ni levo de guerra" (AGI, Ch.30, destacado nuestro). Acto seguido, Muñoz de Ávila enumera los levo de guerra que daban la paz, asegurando que había visto venir las mitas a la ciudad a servir a sus vecinos. La lista de levo es la siguiente:

- Las caveçadas del levo de pedro gonçales dean decano.

- El levo de molculle ques de ortien Ximenez de bertendona.

- El levo de chamavida y leolemu ques de antonio diaz.

- El levo de lincoya ques de anton. Martin y Juan Laso.

- El levo de pangue de Rodrigo de quiroga y fuensalida.

- El levo de billoco ques de Juan Laso.

- El levo de paicavi de Lope de ayala.

- El levo de Pilmaiquen de Juan Nieto y Lope Ruiz muñoz .

- El levo de tucapel ques de Juan albarez de çepeda.

- El levo de Cara.cupil ques de agustin de aumada.

- $\quad$ El levo de Tome de Lope rruiz muñoz.

- El levo de ylicura ques de billegas y garnica.

- El levo de ongolmo ques de Rodrigo de quiroga.

- El levo de rrangalue ques de fuensalida.

- El levo de LleoLeo ques de Xtobal muñoz.
- El levo de bideregua ques de alonso de miranda.

- El levo de claroa ques de gabriel gutierrez. (Juan Muñoz de Ávila al Rey, 30 de Octubre de 1567, fs. [1-2], AGI, Ch.30).

Según este documento, la provincia de Tucapel comprendía por lo menos 17 levo de guerra que al momento de su redacción ya habían sido repartidos entre los españoles, pues figura en cada caso el nombre de su propietario. Se puede apreciar también en este testimonio la existencia de un levo homónimo de la provincia, Tucapel; es importante destacar esta analogía terminológica, pues permite tener en cuenta la existencia de denominaciones idénticas para unidades político-territoriales de diferente amplitud en una misma área, lo que muchas veces puede inducir a confusiones.

En conclusión, se puede afirmar que el levo -en tanto unidad de base de un sistema sociopolítico que articulaba a los grandes conglomerados de población que habitaban los valles fértiles de Nahuelbuta-fue sin duda utilizado y recuperado por los españoles para organizar el sistema de encomiendas y garantizar su efectividad. En términos antropológicos, el levo puede ser definido como una unidad sociopolítica constituida por uno o varios patrilinajes extendidos residentes en un mismo territorio y articulados en torno a una línea de descendencia masculina principal que proveía la jefatura y posiblemente el apelativo. El levo poseía asimismo un componente ritual de gran importancia. Los levo de un mismo gran valle o de un conjunto de valles vecinos conformaban una provincia o, dicho de otro modo, una provincia estaba dividida en levo.

A medida que se acerca el fin del siglo XVI, comienzan a aparecer documentos hispanos etnográficamente más ricos respecto de las poblaciones indígenas rebeldes; en ese marco, emerge el término mapuche ayllarewe -escrito aillaregua-cuya primera referencia ha sido establecida por Palma en 1593 (Palma 1995:53-54) para designar algo muy similar a lo que hasta ese momento se había denominado en español provincia y a veces estado ${ }^{15}$.

Del mismo modo, con el cambio de siglo, la expresión levo tiende a desaparecer y es reemplazada frecuentemente por el término castellano parcialidad. Cuando los autores coloniales quieren expresar el equivalente mapuche del vocablo parcialidad, acuden generalmente a la voz rewe -escrita regua. Se puede suponer entonces que el término rewe 
servirá para designar algo similar a lo que en los primeros tiempos de la conquista se llamaba levo, es decir, aquellas unidades menores que componían las provincias ${ }^{16}$.

\section{Segunda Lectura Hispana de la Realidad Sociopolítica de Nahuelbuta: los Ayllarewe y sus Rewe}

No hemos encontrado indicios del término ayllarewe con anterioridad al último decenio del siglo XVI ${ }^{17}$, período durante el cual Miguel de Olaverría redactó su informe sobre el Reino de Chile (Olaverría 1852:13-54). Este informe marca un giro en la documentación española, pues desde entonces aparecen cada vez más los términos ayllarewe y rewe en sus diversas ortografías y cada vez menos el término levo, hasta casi desaparecer del vocabulario español. Como ya hemos señalado, esto coincide con el surgimiento de una mayor riqueza etnográfica en los relatos hispanos, en particular, en aquellos atribuibles a los escritores jesuitas. Refiriéndose específicamente a la macroárea de la cordillera de Nahuelbuta, Olaverría explica en qué consisten los ayllarewe y cómo operan en esta región. Citemos un párrafo completo de este autor para una mejor comprensión del tema:

Tiene este dicho cuerpo de tierra dos provincias y parcialidades de indios que están fuera del principal, el uno arrimado a Purén que son unas cordilleras arboradas y asperas llamadas los coyuncos en que viven 300 indios poco mas ó menos y el otro es a la parte de la Concessión la tierra referida de Gualqui y Rere y Tarochina que las dichas dos parcialidades tendran mill indios escasos de los mas inquietos y valerosos de todo Chile y es visto que estas dos parcialidades sirven al cuerpo referido del estado de Arauco y Tucapel y Purén en la misma forma que sirven dos cabos o cavalleros a una fortaleza y los dichos estados los tienen y estiman por suyos propios y inclusos en sus parcialidades y número y cuentan dellas y de las allareguas quellos llaman, que la allaregua es una junta y concurso de nueve parcialidades y toda esta tierra referida del estado e indios della están repartidos en cinco allareguas la gente de las cuales por naturaleza y continuo ejercicio en las armas están arrogante, feroz y inquieta y tan inclinados a la guerra que conocidamente se ve ser su elemento y que la quieren y la apetecen (Olaverría 1852:21, destacado nuestro).

Se desprende de la lectura del extracto anterior que además de las tres grandes unidades que, según Olaverría, componían "el estado", es decir Arauco, Tucapel y Purén, había otras dos "provincias" que se encontraban fuera de su jurisdicción pero que formaban parte de sus alianzas guerreras; se trataba, por una parte, de los coyuncos -próximos a Purén- y, por otra, de Gualqui-Rere y Tarochina-, localidades situadas al norte del Bío-Bío. Según este autor, ambas provincias eran consideradas como parte del gran complejo político-geográfico de Nahuelbuta. Sus palabras son elocuentes: "los dichos estados los tienen y estiman por suyos propios y inclusos en sus parcialidades" (Olaverría 1852:21).

En esta parte de su informe, Miguel de Olaverría introduce el término ayllarewe (escribe: allaregua) y señala que con esta denominación los nahuelbutanos se refieren a una alianza ("junta y concurso") de nueve parcialidades, precisando además que todo "el estado" está dividido en cinco ayllarewe. Olaverría no especifica cuáles son estos cinco ayllarewe, pero podemos suponer que se refiere a Arauco, Tucapel y Purén más las dos "provincias" aliadas.

Un documento de 1605, atribuible al Padre Luis de Valdivia, deja en evidencia que lo que los españoles calificaban generalmente como "provincia" correspondía a un ayllarewe y que lo que designaban como "parcialidad" hacía referencia a un rewe. Otra cuestión importante que refiere este texto es que no todas las "provincias" o ayllarewe se componían exclusivamente de nueve "parcialidades" o rewe, sino que las había también constituidas por siete y cinco "parcialidades" o rewe: en el caso de siete, se trataba de un reglerewe (el autor escribe relgueregua) y en el caso de cinco, de un quecherewe, pero a pesar de ello predominaba el término genérico ayllarewe, dice el autor:

Dividieron estos Indios esta tierra para conbocar gente en provincias. A las mas provincias, dividieron en 9 reguas y algunas que no alcansa este numero en $7 \mathrm{y}$ otras en 9. A la provincia de 9 llaman ayllaregua 
porque aylla en su lengua quiere dezir 9 y la de 7 llaman relgueregua porque relgue en su lengua quiere dezir 7 y a la provincia de 5 llaman las quechereguas porque queche quiere dezir 5 (ANCh, M.V.M, Vol. 279, f. 46, destacado nuestro).

Evidencias posteriores, tanto del siglo XVII como del siglo XVIII (Zavala 2000:61-64), nos permiten confirmar que el ayllarewe corresponde a una unidad político-territorial calificada generalmente por los españoles como una provincia (y con posterioridad también como una reducción) compuesta por unidades menores, los rewe o parcialidades. A pesar de la etimología del término ayllarewe (nueve rewe) y del hecho de ser recogido por los españoles como término genérico para referirse a cualquiera de estas unidades político-territoriales o provincias, el ayllarewe no estaba necesariamente constituido por nueve rewe, tal como lo expresa el texto citado anteriormente, lo hemos podido constatar en diversos casos (Zavala 2000:61-64) y lo ha reiterado Goicovich $(2004)^{18}$.

El documento citado anteriormente nombra cada uno de los rewe (el autor escribe: las reguas) que componían los ayllarewe (el autor dice las ayllareguas) que se reunieron a parlamentar con el gobernador Alonso García Ramón y el Padre Luis de Valdivia en el recorrido que éstos realizaron por el territorio de Nahuelbuta en 1605. Sobre la base de este documento y otros tres posteriores de 1612, 1613 y 1614, en los cuales se relatan recorridos similares, hemos construido una tabla comparativa que establece para cada una de las cuatro grandes provincias de Nahuelbuta, ya designadas en esta época como ayllarewe, los rewe o parcialidades que se encontraron presentes en los parlamentos de ese periodo.

En la Tabla 1 se aprecia que a pesar de la diversidad ortográfica con que se transcribieron los nombres de los rewe de cada ayllarewe en los registros hispanos, un gran número de éstos estuvo presente en las reuniones sostenidas con los españoles entre 1605 y 1614, como por ejemplo Arauco, Pengueregua, Quiapo, Quidico, Paicaví, Tirúa, Lleo-Lleo, Rengaloe, Claroa, Purén y Talcamavida. Llama la atención igualmente que en el territorio de Catiray se contabilizaron en 1605 dos unidades político-territoriales distintas: un reglerewe, es decir, una alianza de siete rewe, y un ayllarewe, es decir, una alianza de nueve rewe, si bien a la asamblea de dicho año sólo asistió un rewe de esta última alianza en representación de Catiray.

La información de la segunda mitad del siglo XVI con la de principios del siglo XVII se organiza comparativamente en la Tabla 2. Aquí se ilustra el cambio terminológico ocurrido durante la segunda mitad del siglo XVI para designar las unidades territoriales de base (Levo y Rewe) y la equivalencia que puede establecerse entre la terminología castellana y la mapuche.

Una representación esquemática de estas unidades organizativas partiendo de la más reducida a la más amplia se muestra en la Figura 3. Respecto del nivel superior al ayllarewe, el denominado estado de Arauco en el caso de Nahuelbuta, no podemos afirmar que corresponda a lo que con posterioridad se denominará vutanmapu. Es verdad que la primera referencia a este último término aparece ya en 1613 en un escrito del padre Luis de Valdivia (Boccara 1998:103-104) para dar cuenta de una alianza muy amplia entre el río Bío-Bío y Chiloé. Sin embargo, el denominado estado de Arauco correspondía más bien a un conglomerado relativamente delimitado y acotado a la cordillera de Nahuelbuta y a su área de influencia, lo que no significa que dicho conglomerado no pudiera rearticularse, en ciertas ocasiones, con otros conglomerados para conformar grandes alianzas regionales del tipo vutanтари. En consecuencia, no podemos ratificar la idea planteada por Goicovich $(2002,2006)$ en el sentido de que el estado de Arauco sería ya un vutanmapu -aunque compartamos con él que se trataba de una alianza interlocal-. No nos atrevemos a calificarla de vutanmapu porque este término no aparece explícitamente en este caso y porque posteriormente los vutanmapu adquieren una configuración longitudinal que no corresponde al tipo de sistema confederativo que se dio en torno a la cordillera de Nahuelbuta.

\section{El Caso del Valle de Purén: Contrastación de Materiales Arqueológicos y Etnohistóricos}

De las cuatro grandes provincias que los testimonios españoles del siglo XVI mencionan para dar cuenta de la dinámica interétnica en el sistema de valles de la cordillera de Nahuelbuta -Arauco, Tucapel, Mareguano-Catiray y Purén-, sin duda la última ocupó un lugar exclusivo, tanto por su ubicación geográfica -que la situaba en una cuenca bastante protegida en la parte central de la vertiente oriental de la cordillera- como por 
Tabla 1. Rewe de los cuatro Ayllarewe de Nahuelbuta presentes en reuniones con españoles en el período 1605-1614. Rewes of the four Ayllarewe of Nahuelbuta present at meetings with the Spanish from 1605 to 1614.

\begin{tabular}{|c|c|c|c|c|c|c|}
\hline Ayllarewe & \multicolumn{2}{|c|}{ Rewe } & 1605 & 1612 & 1613 & 1614 \\
\hline \multirow{13}{*}{ ARAUCO } & \multicolumn{2}{|c|}{ Arauco } & $x$ & $x$ & & $x$ \\
\hline & \multicolumn{2}{|c|}{ Colcura } & $x$ & $x$ & $x$ & \\
\hline & \multicolumn{2}{|c|}{ Curilemo } & & & & $x$ \\
\hline & \multicolumn{2}{|c|}{ Chihinmevo } & & $x$ & & \\
\hline & \multicolumn{2}{|c|}{ Lavapie } & $x$ & $x$ & & $x$ \\
\hline & \multicolumn{2}{|c|}{ Lebo } & $x$ & $x$ & & $x$ \\
\hline & \multicolumn{2}{|c|}{ Millarapue } & & & $x$ & $x$ \\
\hline & \multicolumn{2}{|c|}{ Millaregue } & & $x$ & & \\
\hline & \multicolumn{2}{|c|}{ Nideripun } & $x$ & & & \\
\hline & \multicolumn{2}{|c|}{ Pengueregua } & $x$ & $x$ & $x$ & $x$ \\
\hline & \multicolumn{2}{|c|}{ Quiapo } & $x$ & $x$ & & $x$ \\
\hline & \multicolumn{2}{|c|}{ Quirico o Quidico } & $x$ & $\times$ & & $x$ \\
\hline & \multicolumn{2}{|c|}{ Tabuecuo } & $\times$ & & & \\
\hline & \multicolumn{2}{|c|}{ Angolmo } & $x$ & & & \\
\hline & \multicolumn{2}{|c|}{ Bullubueylle } & $x$ & & & \\
\hline & \multicolumn{2}{|c|}{ Cayucupil } & $x$ & & & \\
\hline & \multicolumn{2}{|c|}{ Elicura } & & $x$ & $x$ & \\
\hline & \multicolumn{2}{|c|}{ Libora } & $x$ & & & \\
\hline TUCAPEL & \multicolumn{2}{|c|}{ Lincoya } & $x$ & & & \\
\hline & \multicolumn{2}{|c|}{ Paycaví } & $x$ & $x$ & & $x$ \\
\hline & \multicolumn{2}{|c|}{ Pilmayquen } & $x$ & & & \\
\hline & \multicolumn{2}{|c|}{ Tome molo } & $x$ & & & \\
\hline & Tucar & & $\times$ & & & \\
\hline & Baroa-C & & $x$ & $x$ & & \\
\hline & Boro & & & & $x$ & \\
\hline & Calcuj & & & $x$ & & \\
\hline & Calcuc & & & & $x$ & \\
\hline & Lleo L & & $x$ & $x$ & $x$ & \\
\hline PURÉN & Pellah & & & $x$ & $x$ & \\
\hline & Puré & & & $x$ & $x$ & \\
\hline & Ralon & & & $x$ & & \\
\hline & Rangalme o Ranga & Rengaloe & $x$ & $x$ & $\times$ & \\
\hline & Tirú & & $x$ & $x$ & $x$ & \\
\hline & Vederegua o & gua & & $\times$ & $\times$ & \\
\hline & Reglerewe de Catiray & Caguingueno & $x$ & & & \\
\hline & & Coyenhuereque & $x$ & & & \\
\hline & & Curamlevo & $x$ & & & \\
\hline & & Leubo & $x$ & & & \\
\hline $\begin{array}{l}\text { CATIRAY } \\
\text { Mareouanol }\end{array}$ & & Pirenmanguida & $\times$ & & & \\
\hline [Mareguano] & & Quilimo & $x$ & & & \\
\hline & & $\begin{array}{l}\text { Talcamavida o } \\
\text { Talcamahuida }\end{array}$ & $x$ & $\times$ & & $x$ \\
\hline & Ayllarewe de Catiray & Aremco & $x$ & & & \\
\hline
\end{tabular}

Fuentes utilizadas: 1605: ANCh, M.V.M, Vol. 279. 1612: ANCh, A. M.V.Vol. 2; ANCh, M.V.M Vol. 292; ANCh, F.J. Vol. 93.1613 : ANCh, M.V.M Vol. 293. 1614: ANCh, M.V.M.Vol. 293. 
Tabla 2. Terminología castellana y mapuche para estructuras sociopolíticas según las épocas y su significación. Castillan and Mapuche terminology for socio-political structures for each epoch and their associated meaning.

\begin{tabular}{|c|c|c|c|}
\hline $\begin{array}{l}\text { Castellano } \\
\text { (siglos XVI } \\
\text { y XVII) }\end{array}$ & $\begin{array}{c}\text { Mapudungun } \\
\text { (documentos } \\
\text { tempranos) }\end{array}$ & $\begin{array}{l}\text { Mapudungun } \\
\text { (documentos fines siglo } \\
\text { XVI y siglo XVII) }\end{array}$ & Significación \\
\hline Parcialidad & Levo & Rewe & $\begin{array}{l}\text { Unidad territorial autónoma, articulada en torno a } \\
\text { un patrilinaje principal, que posee un nombre y una } \\
\text { estructura de poder; se reconoce un líder principal. }\end{array}$ \\
\hline Provincia o Estado & - & Ayllarewe & $\begin{array}{l}\text { Conjunto de unidades territoriales autónomas (rewe) } \\
\text { asentadas en un área común, generalmente en una } \\
\text { cuenca hidrográfica. Posee un nombre y una estructura } \\
\text { de poder y opera en conjunto en ciertas ocasiones } \\
\text { políticas y rituales. }\end{array}$ \\
\hline Estado(s) de Arauco & - & - & $\begin{array}{l}\text { Alianza de Ayllarewe de la macroárea de la cordi- } \\
\text { llera de Nahuelbuta estructurada en torno a cuatro } \\
\text { grandes valles: Arauco, Tucapel, Mareguano-Catiray } \\
\text { y Purén. }\end{array}$ \\
\hline
\end{tabular}

\begin{tabular}{|c|c|}
\hline $\begin{array}{c}\text { Según documentos tempranos } \\
\text { (s. XVI) }\end{array}$ & $\begin{array}{c}\text { Según documentos posteriores } \\
\text { (fines s. XVI y principios s. XVII) }\end{array}$ \\
\hline Levo & Rewe \\
$\downarrow$ & $\downarrow$ \\
Provincia o Estado & Ayllarewe \\
$\downarrow$ & $\downarrow$ \\
Estado(s) de Arauco & Estado(s) de Arauco \\
& \\
\hline
\end{tabular}

Figura 3. Niveles de inclusión sociopolítica según terminologías de los siglos XVI y XVII.

Levels of socio-political inclusion according to 16th and 17th Century terminology.

la amplitud y riqueza de su territorio, cuyo piso anegable contaba con ciénegas e islas interiores que tuvieron una función estratégica en el accionar militar mapuche.

Desde los inicios de la conquista española a mediados del siglo XVI, cruzaba el valle un camino principal (camino real) que unía Concepción con la Imperial; dicho camino bordeaba la cordillera de Nahuelbuta por el oeste, pasando por Angol. Pero igualmente esta vía podía empalmar con el camino de la costa, a través del paso de Contulmo, uniendo así Concepción, Arauco, Cañete, Purén e Imperial. En su trayectoria por el valle de Purén, el camino real seguía el curso del río Purén-Lumaco.
Con toda certeza, estas vías de comunicación existían con anterioridad a la llegada de los españoles, pues en ningún caso los documentos señalan trabajos para abrir caminos, y la gran velocidad con la cual se desarrollaron las exploraciones y conquistas españolas sólo puede explicarse por la preexistencia de un sistema de rutas bien mantenidas.

El registro arqueológico para el período prehispánico tardío permite decir que la cultura desarrollada en el valle de Purén-Lumaco es representativa de procesos sociales que habían estado en marcha en los Andes centrales y meridionales durante siglos (Dillehay 1985, 2003, 2007). En 
efecto, entre 1.300 y 1.600 d.C. la población creció, el intercambio interregional se intensificó, las costumbres mortuorias se hicieron cada vez más elaboradas, la dependencia de la horticultura se incrementó y las organizaciones sociales y ceremoniales así como las relaciones intergrupales se volvieron más complejas. Algunos de estos procesos se dieron con mayor intensidad y de manera singular en ciertas áreas específicas de La Araucanía, como fue el caso del valle de PurénLumaco, donde el registro arqueológico muestra algunos elementos culturales como montículos ( $k u e l)$, fortalezas, grandes aldeas domésticas, campos agrícolas elevados, que los separan no sólo de otras culturas indígenas de Chile central, sino también de otras culturas de montículos de la región araucana.

En el valle de Purén-Lumaco se han registrado más de 300 kuel o montículos individuales, 78 de los cuales se hallan agrupados en nueve -y posiblemente diez- complejos de rewekuel (o rehuekuel) que son agrupaciones de montículos en un cerro extensivamente modificado (Dillehay 2001, 2007). Hemos documentado una transformación de montículos funerarios o kuel y de espacios rituales pequeños y aislados con más de ochenta fechados con radiocarbono y termoluminiscencia (TL) entre los siglos XII a XIX d.C. Del mismo modo, hemos registrado rewekuel y asentamientos domésticos relativamente extensos fechados entre los siglos XV y XVII d.C. Los kuel pequeños y aislados más tempranos se encuentran asociados con la agricultura incipiente, comunidades dispersas y una complejidad social emergente. Los complejos rewekuel posteriores están definidos por ubicaciones específicas, una distribución restringida y equidistante en el valle, dimensiones relativamente estandarizadas, paisajes ceremoniales y la complejización de la estructura política (Dillehay 2007). El desarrollo de estos complejos es un vigoroso indicador arqueológico de un sistema político bien integrado y organizado, que se hallaba en funcionamiento al menos entre los siglos XV y XVI d.C. Estos complejos o bien no se dan en otros valles o bien están presentes de modo disperso y con baja densidad en lugares tales como Rucaray (en la costa del Pacífico al oeste de Purén), Boyeco y Chol-Chol (cerca de Temuco), y en Pucón (cerca de la frontera argentina), lo que sugiere en estos últimos casos la existencia de comunidades pequeñas, algunas dispersas y otras nucleadas, con menor desarrollo cultural y menor centralización política (Dillehay 1985, 1995, 1999).

Es bien conocido en el mundo arqueológico que la presencia de estas características de monumentalidad, densidad de poblaciones domésticas, estandarización de bienes materiales y símbolos, sistemas infrastructurales de defensa y de agricultura, etc. reflejan directa o indirectamente el surgimiento de "cacicazgos mayores" y/o "polities" semicentralizadas o centralizadas y confederadas políticamente (p.ej. Chapman 2003; Moseley 1992; Tilley 1994; Yoffee 2005).

Como hemos señalado en publicaciones anteriores (Dillehay 2007), la mayoría de los kuel están construidos sobre promontorios nichi que flanquean las ciénagas en el piso del valle. Los montículos varían en tamaño entre los 8 y los 50 $\mathrm{m}$ de diámetro, y 1 y $15 \mathrm{~m}$ de alto. Los rewekuel a menudo están orientados con sus largos ejes paralelos o perpendiculares hacia un cuerpo de agua, generalmente un río o pantano. El hecho de que una serie de yacimientos de montículos, de sitios domésticos, de cementerios y ocasionalmente de sitios defensivos aparezcan en cada complejo rewekuel y alrededor de éstos sugiere que los estímulos medioambientales y los factores que afectaban el sistema -entre ellos, la guerra y la práctica de la agricultura de riego- eran esencialmente similares para todo el valle. En efecto, la naturaleza interna de los nueve a diez rewekuel que caracterizan los patrones de subsistencia-asentamiento, sugiere no sólo un notable grado de similitud de área a área en los sectores del valle de Purén-Lumaco, sino también la probabilidad de que cada rewekuel haya operado tanto independientemente como en forma complementaria con otros. Es relevante destacar que varios de estos rewekuel (Tren-Trenkuel, Loncoyankuel y Hualonkokuel) son actualmente utilizados como espacios ceremoniales donde se realizan guillatun (rogativas) y juegos de palin.

Los kuel y rewekuel constituían el marco de una organización simbólica que se actualizaba a sí misma gracias a la actividad humana (Dillehay 2007), ya fuera a través del reclutamiento o la adopción de refugiados y desplazados por parte de patrilinajes residentes, la construcción de alianzas entre patrilinajes, o bien la circulación de fiestas ceremoniales a lo largo y ancho del valle. La actividad humana dentro del valle y con otros valles vecinos estuvo orientada por estos "arreglos 
arquitectónicos" sagrados, pero dicha arquitectura era en sí misma un producto de las especificidades y ritmos temporales dados por la cosmología y la historia indígenas. Fue precisamente cuando dichas cosmología e historia cristalizaron en normas, saberes, valores y reconocimiento de genealogías, que surgió un nuevo paisaje conceptual y ritual, y que la organización política araucano-mapuche comenzó a estructurarse en esta zona para irse transformando, consolidando y ampliando a lo largo del tiempo. Fueron las prácticas sociales surgidas en torno a la compleja geografía sagrada del valle las que permitieron organizar un territorio densamente poblado, como muestran los sitios arqueológicos del valle (Dillehay 2007).

El registro etnohistórico permite señalar el carácter particularmente guerrero de los habitantes de la provincia de Purén durante los siglos XVI y XVII. Esto aparece generalmente asociado con prácticas rituales o estilos de vida que hacen pensar en una sociedad donde existía un sistema cultural construido en torno a la acción guerrera. Muchas de estas características también son atribuidas a las otras provincias nahuelbutanas, en particular a Tucapel, pero los observadores españoles tienden a destacar el papel fundamental de los habitantes de Purén en la resistencia a la conquista.

Al respecto, cabe citar un testimonio relativamente temprano (hacia 1577) que relata los sucesos acaecidos durante el gobierno de Francisco de Villagra (1561-1563), cuando los grupos de Tucapel y Purén se convocaron para la guerra. El documento señala:

[...] hizieron luego la solemnidad que suelen uzar que es esta matan una obeja de la tierra y sacanle el corazón y todos los caciques y hombres principales en nombre de todos los demás untan las [flechas] en la sangre de la dicha obeja en señal de que / cumplieron lo acordado y guardarán secreto y que serán perpetuos enemigos de los españoles y questa horden guardarán mientras tubieren vida y luego hechan la cabeza de la obeja muerta en medio de un llano y toman sus harmas aquellos señores que son lanzas y [soplaban] caracol redondo con un estruendo muy grande y dan de lanzadas aquella cabeza [durante] que se les saltan ambos los ojos y entonzes tienen por cierta la istorria subese un Indio Predicador en

\begin{abstract}
un palo muy alto quedando al rrededor del todos los señores y en nombre de todos dize á la comunidad lo acordado, todos responden questá muy bien dicho y acordado y ansi cada señor da dé bever á su jente por su propia mano en señal que ansi como cabe aquella bebida en sus cuerpos quepa el guardar secreto. (Francisco de Bilbao a su Majestad, s. f. [hacia 1577], ANCh, MVM, vol. 267, f.161-162, destacado nuestro).
\end{abstract}

Queda retratado en este pasaje el ritual que posteriormente será descrito en numerosos documentos coloniales y que muestra los mecanismos de decisión altamente ritualizados utilizados por los mapuches. Cabe destacar la referencia a un "indio predicador" que se sube a "un palo muy alto"; la similitud con el rewe y con la "ascensión" a este del machi actual parece evidente. Ese "indio predicador" tiene el "don de la palabra", de una palabra "autorizada" y en su discurso convoca a los presentes a asumir la acción que su palabra propone; el "acuerdo" se sella con el acto de "beber" que cada "señor" debe "aportar a su gente" por "su propia mano". Este tipo de actividad, en que mecanismos de decisión política -en particular guerrera- y actividad ritual se mezclan, será descrito en diferentes épocas de la historia mapuche. En el mismo documento queda de manifiesto la importante participación de los habitantes de Purén en la resistencia a la conquista hispana:

[...] los del valle de puren mataron a su amo don pedro de avendaño capitán famoso y asus amigos que estaban descuydados con él en el dicho valle y por la propia horden al capitan Pedro esteban con sus amigos que assi [----------] descuydado delos Indios de su encomienda y los que no podían áver despaña les mataban los Indios forasteros que los mandaban en lugar de sus amos y ansi publicaron la guerra de tal manera que hasta el día de oy dura aunque algunas vezes an dado la paz y de nuevo buelven por la propia horden que arriba he dicho.... (Francisco de Bilbao a su Majestad, s. f. [hacia 1577], ANCh, MVM, vol. 267, f.162-163). 
Para una caracterización de los habitantes de la provincia de Purén y de las otras provincias del estado nahuelbutano a fines del siglo XVI, corresponde remitirse necesariamente al texto de Miguel de Olaverría de 1594 o 1598, el cual señala que:

[...] se a visto por experiencia acometer en Purén solos seis indios naturales de aquella provincia a vista de muchos españoles a 300 indios de las ciudades Imperial, Ricca, Valdivia y Osorno y hacerles huir matando algunos dellos, sobre los quales indios de las ciudades dichas y sobre otros comarcanos suyos tienen tanta superioridad, merced y señorío los del estado que cada vez que lo quieren les hacen quebrantar la paz y que deguen de servir a los españoles como por experiencia se ha visto ora cercándoles por el rigor de las armas e por pagas é interesses que les dan donde evidencia ser cobardes y de poca importancia todos los indios de Chile que no sean del estado o comarcanos del (Olaverría 1852:22).

Este autor diferencia marcadamente a los habitantes del estado, en particular a los de Purén, respecto de los grupos de más al sur en cuanto a su capacidad para la acción guerrera.

En un documento contemporáneo (1598), el gobernador García de Loyola relata la relación existente entre las diversas provincias de Nahuelbuta en las acciones de resistencia; en particular, García señala una suerte de complementariedad entre actividades productivas y militares que permitían la especialización guerrera de los habitantes de Purén cuando dice que "[...] era notorio la ayuda que daban [los Tucapeles] á los purenes y que les hazían sus sementeras en el estado de tucapel" (García de Loyola al Rey, 17/01/1598, ANCh, MVM, vol. 273, f.67).

Por otra parte, la descripción de fray Diego de Ocoña, fechada en 1600, merece reproducirse por su riqueza respecto de la relación de los habitantes de Purén con la ciénega y va en el mismo sentido de las descripciones anteriores:

\section{[La ciénaga de Purén] Es la mayor fuerza que tienen en este Reyno por que es una laguna grande, muy hondable y con muchas islas dentro en las cuales habitan los indios y con canoas se sirven, por que las sementeras las}

hacen alrededor de la laguna y el ganado ovejuno y porcino y algunos cabríos questos indios tienen se pasta en tierra alrededor de la laguna y está tan hecho este ganado a embarcarse y desembarcarse en las canoas cada noche y a la mañana el mesmo se entra a las canoas y los indios no tienen mas trabajo que llevallo y traello y si alguno reparase en cómo esta laguna no se ha conquistado es la / causa que un cuarto de legua alrededor de ella es todo de pantanos y lodo hasta la punta y grandes carrizales, una vez que han probado los españoles a entrar por estos lodazales llegaron a las islas, los indios se fueron con sus canoas a la otra parte y se metieron por las montañas se vuelven a la laguna y desta suerte no se pueden dar alcance y no se pueden conquistar. Tiene otra cosa esta laguna que como los indios son muchos y las islas pocas no caben en ellas y la necesidad les ha hecho en algunos bajíos que tiene esta laguna donde hay grandes arrayanes entre las ramas dellos hacen unas barbacoas a donde hacen sus casas y aquí habitan los que no pueden en las islas y asi son estos indios muy belicosos por esta ocasión que tienen desta fortaleza desta laguna que la naturaleza parece que puso allí para defensa suya (fray Diego de Ocoña 1995:38-39).

Estas islas al interior de la ciénaga en efecto constituyeron áreas de habitación densamente pobladas y con gran actividad agrícola, como lo demuestran los sitios arqueológicos elevados que hemos encontrado en el piso del valle (Dillehay 2007).

\section{Conclusiones}

En términos generales, es posible decir que durante el periodo prehispánico tardío e inmediatamente posterior, la estructura sociopolítica de los araucano-mapuches consistía en una suerte de duplicación a niveles cada vez más altos de incorporación política y religiosa de una unidad política local, levo o rewe, que aglutinaba uno o varios patrilinajes vecinos bajo la autoridad de un jefe o representante; diversos levo de un mismo valle o territorio podían reunirse en una provincia o ayllarewe. Algunas provincias fueron capaces 
de confederarse en una unidad mayor, que para el caso nahuelbutano se llamó estado(s) de Arauco. Parece ser que un principio ordenador de estas macrounidades confederativas fue el de una composición cuatripartita similar a la del mundo andino, al menos así lo mostraría el caso de la cordillera de Nahuelbuta.

Desde esta perspectiva, reviste particular interés el proceso a través del cual ayllarewe más grandes y complejos asentados en valles tales como Arauco, Tucapel, Mareguano-Catiray y Purén procedieron tempranamente durante el siglo XVI a reclutar y anexar agrupamientos más pequeños en áreas periféricas, con lo que se provocó la fisión y dispersión de estos últimos y fue posible la creación de grandes alianzas. Al parecer, otras poblaciones carecían de un centro de atracción importante y en consecuencia conformaban una gran nube de pequeñas estructuras políticas satelitales dispersas en torno a las grandes alianzas que se constituían en los territorios de la cordillera de Nahuelbuta y que los españoles designaron con el nombre de estado(s) de Arauco. Este patrón ilustra las características fundamentales de una estructura política regional difusa, segmentada y confederada. En otras palabras, la estructura política araucano-mapuche comprendía agrupamientos regionales de corta duración y patrilinajes de larga vida -algunos de ellos actuaban solos y otros se aliaban en entidades más grandes- entregados todos a la causa de defender su tierra natal y de esforzarse por sostener una organización política unificada mayor. El resultado fue una suerte de confederación de organizaciones geopolíticas cada vez más grandes, organizadas primero a nivel local y luego a nivel de una misma cuenca hidrográfica hasta llegar, en ciertas ocasiones, a niveles regionales mayores al agrupar a varias cuencas articuladas en torno a un mismo sistema cordillerano.

En el caso de la cordillera de Nahuelbuta, esta alianza de cuencas vecinas fue pensada sobre la base de una división en cuatro grandes componentes: Arauco, Tucapel, Mareguano-Catiray y Purén. Esto calza aproximadamente con una división del espacio nahuelbutano en cuatro subsectores: noroeste, suroeste, noreste y sureste, lo que supone, a nuestro entender, que existía ya en esta época una conceptualización cuatripartita del territorio que posteriormente se manifestaría en diversos dominios del pensamiento mapuche ${ }^{19}$.

Por otra parte, no es gratuito que el valle de Purén-Lumaco sea reconocido históricamente como uno de los principales centros de resistencia contra la conquista hispana. Hay una razón por la que este valle fue uno de los primeros y más constantes en el rechazo de los españoles. La cuenca del río Purén-Lumaco era una de las áreas política y económicamente más avanzadas del sur de Chile en la época prehispánica tardía y, por ende, ya contaba con una condición organizativa y una densidad demográfica suficiente no sólo para resistir sino también para liderar a otros grupos, con lo que pudo vencer y expulsar a los españoles. Las dinastías patrilineales de este valle no solamente dejaron su legado político en tradiciones orales y fuentes escritas, sino también en la geografía de montículos político-religiosos que levantaron y dominaron. Como todo antropólogo o historiador sabe, este tipo de geografía indica una complejidad social muy por encima del nivel de cazadores y recolectores. Ello indica trabajo corporativo, riqueza, jerarquía, densidad poblacional y otros rasgos típicos de sistemas sociales de gran talla. En su geografía, los araucano-mapuches codificaron todos estos elementos, así como su historia de lucha y cambio, de tal modo que el pasado se encuentra con el presente en el terreno sagrado del valle de Purén.

Agradecimientos: Esta investigación ha sido iniciada en el marco del proyecto arqueológico, paleoecológico y etnohistórico Purén-Lumaco financiado por la National Science Foundation y la National Geographic Society y continuada en el marco del proyecto FONDECYT n ${ }^{\circ} 1090504$ "Espacios interétnicos de encuentro y negociación en La Araucanía: génesis, transformaciones y significaciones de los parlamentos hispano-mapuches coloniales", nuestros agradecimientos a dichas instituciones por su importante apoyo así como también al Consejo de Monumentos Nacionales de Chile y a las Comunidades Mapuches de las comunas de Los Sauces, Lumaco y Purén por sus respectivas autorizaciones y su gran cooperación en el desarrollo de esta investigación. Agradecemos especialmente a Carmen Gloria Garbarini, Daniel Videla, Yeniè Norambuena y Natalia Zavala por sus preciadas colaboraciones en la revisión y presentación de diversos aspectos de este artículo. También deseamos agradecer el destacado y dedicado trabajo de revisión hecho por los evaluadores de este artículo, sus comentarios y sugerencias lo han enriquecido. 


\section{Referencias Citadas}

\section{Archivo General de Indias, Sevilla (AGI)}

- Audiencia de Chile (Ch.), legajos 18, 30 y 31.

Archivo Nacional de Chile (ANCh)

- Archivo Morla Vicuña (AMV), vols. 1 y 2.

- Fondo Jesuita (FJ), vol. 2.

- Manuscritos Vicuña Mackenna (MVM), vols. 267, 273, 279, 292 y 293

Barros Arana, D. 1999 [1884-1902] Historia General de Chile. Editorial Universitaria, Santiago.

Bengoa, J.

2003 Historia de los Antiguos Mapuches del Sur. Catalonia, Santiago.

Boccara, G.

1998 Guerre et Ethnogenèse Mapuche dans le Chili Colonial: L'Invention du Soi. L'Harmattan, París.

Cobarruvias, S.

1994 [1611] Tesoro de la Lengua Castellana o Española. Editorial Castalia, Madrid.

Chapman, J.

2003 Complexity in Archaeology. Cambridge University Press, Cambridge.

Dillehay, T.

1985 Cuel. Observaciones y comentarios sobre los túmulos en la cultura Mapuche. Chungara 16-17:181-193.

1995 Mounds of social death: Araucanian funerary rites and political Succession. En Tombs for the Living: Andean Mortuary Practices, editado por T. Dillehay, pp. 281-313. Dumbarton Oaks, Washington, D.C.

1999 El paisaje cultural y público: el monumentalismo holístico, circunscrito de las comunidades Araucanas. En Arqueología de las Tierras Bajas, editado por A. Durán y R. Bracco, pp. 451-468. Ministerio de Educación y Cultura, Comisión Nacional de Arqueología, Montevideo.

2001 Informe Preliminar de 1996-2004 del Proyecto Purén y Lumaco. Presentado al Consejo Nacional de Monumentos Nacionales, Santiago.

2002 Una historia incompleta y una identidad cultural sesgada de los Mapuche. En Colonización, Resistencia y Mestizaje en las Américas, Siglos XVI-XX, editado por G. Boccara, pp. 163-184. Ediciones Abya-Yala, Ecuador.

2003 Informe Técnico sobre el Proyecto Purén y Lumaco, 2002. Informe presentado al Consejo Nacional de Monumentos, Santiago.

2007 Monuments, Empires and Resistance: Araucanian Polity and Ritual Narratives. University Press, Cambridge.

2008 Informe Final del Proyecto Puren-Lumaco, Provincia de Malleco. En posesión del Consejo Nacional de Monumentos, Santiago.

Ercilla y Zúñiga, A.

1845 La Araucana. Imprenta de Manuel Sauri, Barcelona.

Foerster, R.

2004 ¿Pactos de Sumisión o Actos de Rebelión?: una Aproximación Histórica y Antropológica a los Mapuches de la Costa de Arauco, Chile. Tesis para optar al grado de Doctor en Antropología, Universidad de Leiden, Holanda.
Goicovich, F.

2002 La etapa de la conquista (1536-1598): origen y desarrollo del "Estado indómito". Cuadernos de Historia 22:53-110.

2004 Reevaluación etnohistórica de las Ayllareguas RecheMapuches. Actas V Congreso Chileno de Antropología Tomo I, pp. 559-565, Colegio de Antropólogos de Chile, Santiago.

2006 Alianzas geoétnicas en la segunda rebelión general: génesis y dinámica de los vutanmapus en el alzamiento de 1598. Revista Historia 39:93-154.

Góngora Marmolejo, A.

1990 Historia de Todas las Cosas que han Acaecido en el Reino de Chile y de los que lo han Gobernado (1536-1575). Ediciones de la Universidad de Chile, Santiago.

Grebe, M.E.

1973 El kultrún mapuche: un microcosmo simbólico. Revista Musical Chilena 123-124:3-39.

Guarda, G.

1990 Flandes Indiano: las Fortificaciones del Reino de Chile 1541-1826. Ediciones Universidad Católica de Chile, Santiago.

Krumm, G.

1971-1972 División territorial de La Araucanía. Revista Chilena de Historia y Geografía 139:86-104 (1971) 140:50-71 (1972).

Latcham, R.

1924 La Organización Social y las Creencias Religiosas de los Antiguos Araucanos. Imprenta Cervantes, Santiago.

Lumbreras, L.

1981 Arqueología de la América Andina. Editorial Milla Batres, Lima.

Maquiavelo, N.

1961 El príncipe. En Obras. Editorial Vergara, Barcelona.

Mariño de Lobera, P.

1960 [1580] Crónica del reino de Chile, escrita por el capitán D. Pedro Mariño de Lobera. En Crónicas del Reino de Chile, editado por F. Esteve Barba, pp. 225-262. Editorial Atlas, (Biblioteca de autores españoles, 131), Madrid.

Medina, A.

1974-75 El Estado Araucano. Boletín de Prehistoria de Chile 7-8:141-154

Moseley, M.E.

1992 The Incas and their Ancestors. Thames and Hudson, London.

Murra, J.

1975 Formaciones Económicas y Políticas del Mundo Andino. IEP, Lima.

Menghin, $\mathrm{O}$.

1959-1960 Estudios de prehistoria araucana. En Acta Prehistórica 3:49-120

Netherly, P.J.

1993 The nature of the Andean State. En Configurations of Power Holistic Anthropology in Theory and Practice, editado por J. Henderson y P. Netherly, pp. 11-35. Cornell University Press, Ithaca y Londres.

Obregón-Iturra, J y J.M. Zavala.

2009 Abolición y persistencia de la esclavitud indígena en Chile colonial: estrategias esclavistas en la frontera araucanomapuche. Revista Memoria Americana 17:7-31. 
Ocoña, D. Fr.

1995 Viaje a Chile: Relación del viaje a Chile, año de 1600.

Editorial Universitaria, Santiago.

Olaverría de, $\mathrm{M}$.

1852 Informe de Don Miguel de Olaverría sobre el reyno de Chile, sus indios y sus guerras (1594). En Claudio Gay, Historia Física y Política de Chile, Vol. 2, pp. 13-54. Casa del Autor, París.

Palma, D.

1995 La Rebelión Mapuche de 1598. Tesis para optar al grado de Licenciado en Historia, Instituto de Historia, Pontificia Universidad Católica, Santiago.

Petit-Breuilh, M.E.

1997 Lavaderos de oro en La Araucanía: un enfoque históricogeográfico. Siglo XVI hasta principios del siglo XX. Actas del VIII Congreso Geológico Chileno, Vol. 2, pp. 1099-1103. Universidad Católica del Norte, Antofagasta.

Quiroga, J.

1789 Compendio histórico de los más principales sucesos de la conquista y guerras del reyno de Chile hasta el año 1656 sacados del manuscrito del maestre de Campo Don Gerónimo de Quiroga. En Semanario Erudito, que Comprende Varias Obras Inéditas, Críticas, Morales, Instructivas... de Nuestros Mejores Autores Antiguos y Modernos dadas a la luz por Don Antonio Valladares de Sotomayor, Tomo 23, pp. 163-249. Blas Roman, Madrid.

Real Academia Española

1979 [1726 a 1739] Diccionario de la Lengua Castellana, en que se Explica el Verdadero Sentido de las Voces. Edición Facsimilar, Madrid.

Rostowrowski, M.

1988 Historia del Tahuantinsuyu. IEP, Lima.
Sánchez Agesta, L.

1959 El Concepto del Estado en el Pensamiento Español del siglo XVI. Instituto de Estudios Políticos, Madrid.

Tilley, $\mathrm{T}$.

1994 A Phenomenology of Landscape: Places, Paths and Monuments. Berg Press, Oxford.

Valdivia, L.

1887 Arte, Vocabulario y Confesionario en la Lengua de Chile. B.G. Teubner, Leipzig.

Valdivia, $\mathrm{P}$.

1992 Cartas de Relación de la Conquista de Chile. Edición crítica de Mario Ferreccio P. Editorial Universitaria, Santiago.

Vicuña Mackenna, B.

1932 La Edad del Oro en Chile, Tomo 1. Biblioteca Vida Chilena, Santiago.

Vitoria, F.

1934 [1539] Relección I de Indis, Tomo II, 2 a 9. Getino, Madrid.

Vivar, G.

1979 [1558] Crónica y Relación Copiosa y Verdadera de los Reinos de Chile (1558). Edición y notas de Leopoldo Sáez-Godoy. Colloquium Verlag. XIX (Biblioteca Iberoamericana, 27), Berlín.

Yoffee, $\mathrm{N}$.

2005 The Myth of the Archaic State. Cambridge University Press, Cambridge.

Zavala, J.M.

1998 L'envers de la Frontière du royaume du Chili: les cas des traités de paix hispano-mapuches du XVIIIe siècle. Histoire et Société de l'Amérique Latine 7:185-208.

2000 Les Indiens Mapuche du Chile. L'Harmattan, París.

2008 La cordillera de Nahuelbuta, ¿lugar de naturaleza o de cultura?: concepción del espacio cordillerano en fuentes españolas del siglo XVI. Revista CUHSO 15:17-24.

\section{Notas}

1 Entre las crónicas y escritos más conocidos de los primeros decenios de conquista se encuentran: Ercilla (1845 [1569]); Góngora Marmolejo, 1990 [1575]; Mariño de Lobera 1960 [1580]; Olaverría (1852 [1594]); P. de Valdivia 1960 [15501552]; Vivar 1979 [1558].

2 Sería inagotable referir la cantidad de trabajos. Sólo señalamos los más directamente relacionados con el tema abordado en este artículo: Bengoa (2003); Boccara (1998); Foerster (2004), Goicovich (2002, 2004 y 2006); Krumm (1971-72); Latcham (1924); Medina (1974-75); Palma (1995).

3 Durante los siglos XVI y XVII, los mapuches no son designados como tales. En general, los españoles se limitan a llamarlos "indios de la tierra" o "indios de Chile". El término "mapuche" no aparece en la literatura etnográfica sino a fines del siglo XIX. Por otra parte, el vocablo "araucano" tampoco es utilizado durante los siglos coloniales como término genérico para referirse al conjunto de los mapuches, puesto que se reserva por lo general para los habitantes de la "provincia" de Arauco, aunque poco a poco, particularmente a partir de la publicación de las paces de Quillín de 1641 y sobre todo de la historia del Abate Molina, el término parece haberse popularizado en Europa y comenzado a aplicarse en Chile al conjunto de los grupos ubicados entre los ríos Bío-Bío y Toltén (Zavala 2000). Con la finalidad de no crear más confusión al respecto, hemos adoptado el término compuesto "araucano-mapuche", propuesto por nuestra colega Jimena Obregón-Iturra (Obregón-Iturra y Zavala 2009), que tiene la ventaja de dar cuenta de una sola vez de los dos etnónimos de mayor difusión en la literatura especializada en inglés y en castellano para referirse a los habitantes de La Araucanía.

4 El documento publicado por Claudio Gay aparece fechado en 1594, pero un análisis crítico hecho por Daniel Palma tiende a señalar que al menos una buena parte de él, habría sido redactado a principios de 1598 (Palma 1995:26).

5 Hemos analizado en detalle ambos textos en José Manuel Zavala (2008).

$6 \quad$ Nos hubiese gustado conocer con mayor anterioridad el trabajo de Goicovich (2002), pues hemos realizado una lectura similar de la obra de Ercilla sin conocer su artículo. No compartimos, sin embargo, la utilización que hace este autor de conceptos tales como wichanreguas y vutanmapu que son posteriores, para describir instituciones indígenas 
tempranas del siglo XVI, pues aunque supongamos que están presentes, los documentos nos entregan otras denominaciones.

7 Hay que decir que el término "estado" se usa algunas veces en los documentos del siglo XVI con referencia al área como sinónimo de "provincia"; pero en otras supone un conjunto de "provincias". De esta manera, a veces el "estado de Arauco" es equivalente a la "provincia de Arauco" y otras supone la provincia de Arauco más las otras "provincias vecinas"; en este último caso, se utiliza también el plural, es decir, "los estados" de Arauco.

8 Pero también debemos decir que parece ser que el concepto de estado, como equivalente de república, comienza a generalizarse más en España a partir de la segunda mitad del siglo XVI con la recepción del pensamiento de Maquiavelo quien habla de "lo stato" para designar con este vocablo el status político, y con ello a la organización del poder político (Maquiavelo 1961:158).

9 El diccionario de autoridades dice: "Republica. El gobierno del público. Oy se dice del gobierno de muchos, como distinto del gobierno monárquico" y agrega "Por extensión se llaman también algunos pueblos" (RAE tomo III, 1979 [1737]).

10 Los autores citados por Medina (1974-75:151-152) que dan esta explicación a la denominación de "estado de Arauco" son los siguientes: Melchor Jufré del Águila (1630), Diego de Rosales (1670), Pedro de Córdoba y Figueroa (1745) y Diego Barros Arana (1884). Cabe agregar que al referirse al término "araucano", Alberto Medina (1974-75:152) dice que así se designaba en un principio a los indígenas pertenecientes a las parcialidades de Arauco y Tucapel "denominados el estado o los estados" y que luego dicho calificativo se habría ampliado a "todos los indígenas cuyo hábitat era la cordillera de Nahuelbuta".

11 El territorio cubierto por Mareguano aparece en muchos documentos asociado a Catiray, por ello hemos optado en utilizar el término compuesto "Mareguano-Catiray". Por otra parte, aunque en menor medida, Mareguano y Catiray aparecen asociados en algunos textos al territorio de Millapoa.

12 En efecto, en el extracto de la relación de Luis de Valdivia que reproduce Guillaume Boccara (1998:103-104) aparece que la tierra de guerra se organiza en tres utanmapus, lo cual parecería confirmar la teoría de F. Goicovich (2002) respecto de que son tres las "provincias" que sustentarían el estado de Arauco; sin embargo, el propio Goicovich cita a continuación del extracto antes señalado, otro texto del mismo jesuita donde se señala que son cuatro "cabezas" las que dirigen la tierra de Guerra (Goicovich 2002:90-91).

13 Al respecto, cabe señalar que aunque Lumbreras (1981:103112) clasificó al área mapuche como "Área Extremo Sur Andina” y asoció la cerámica El Vergel con los Andes
Meridionales, esta clasificación no tiene mayor relevancia ya que este autor nunca consideró ciertas tendencia presentes en los Andes Centrales y los Andes Centro-Sur CircumTiticaca y que se encontraban igualmente en La Araucanía como lo han postulado otros autores (Dillehay 1976, 1990; Menghin 1959-1960).

14 En la cordillera de Nahuelbuta y su área de influencia se establecieron importantes explotaciones auríferas. PetitBrueilh (1997:1101) señala la existencia de lavaderos de oro hispanos o posthispanos en Butamalal, Arauco, río Tirúa, Purén, Pichi-Pellahuén, Capitán Pastene, Nilpe, confluencias de los ríos Repocura con Imperial, Carahue, Cholchol y Boroa.

15 Ricardo Latcham en su estudio sobre la organización social de los antiguos araucanos (1924), reconoce ya como ayllarewe a las denominadas "provincias" indígenas existentes a la llegada de los españoles pero no señala ninguna fuente del siglo XVI donde aparezca el término. Para este autor, entre el río Itata y el seno de Reloncaví habrían existido en total unos 50 a 51 ayllarewe, de los cuales él logra establecer una lista de 46 y una tercera parte de los 470 levo que los habrían constituido (Latcham 1924:140).

16 Latcham (1924) reconoce este cambio terminológico y establece la relación entre los términos levo y rewe, señalando que a comienzo del siglo XVII la voz levo decayó en favor de rewe y cita el vocabulario del padre Luis de Valdivia para dar la definición de levo: "Lebo, parcialidad y división de tierras" (Latcham 1924:128). Para este autor, la palabra levo sería una deformación del término mapuche lepun, que es el lugar de la junta de dicha agrupación (Latcham 1924:127). Foerster (2004:50) reconoce igualmente que los términos levo y rewe sirven para denominar un mismo nivel de organización social.

17 Como ya lo señalamos, debemos a Daniel Palma la ubicación del primer registro del término, en la declaración de dos mulatos "que vivían entre los indios rebelados" del 27 de diciembre de 1593 (Palma 1995:53-54).

18 Goicovich (2004:559-565) propone reemplazar el término ayllarewe, que cree induce a error, por el término wichanregua, creación suya, pues sería más neutral y serviría de categoría de análisis. Goicovich piensa que la utilización insistente de ayllarewe (ayllareguas) es una equivocación hispana, una suerte de inercia histórica por utilizar un concepto que no es apropiado. En ningún caso se plantea que la aparición insistente del término en las fuentes se deba a que los mapuches lo utilizaban en un sentido genérico.

19 Nos referimos específicamente a la organización de los mapuches de La Araucanía en Cuatro vutanmapu durante el siglo XVIII y a la representación simbólica que muestra la superficie del kultrun de los(as) actuales machi. 